\title{
MÍDIA, CONSUMO E CRIME NA JUVENTUDE: a construção de um traçado teórico
}

\author{
Patricia Bandeira de Melo* \\ Rodrigo Vieira de Assis ${ }^{* *}$
}

\begin{abstract}
Refletir sobre o consumo na modernidade abre caminho para pensar a possibilidade de surgimento de ações criminosas como meio de acesso a bens, ofertando a alguns indivíduos a chave de entrada a grupos sociais dos quais somente é possível pertencer através da posse de elementos distintivos. O objetivo deste artigo é discutir conceitos que sejam capazes de relacionar a comunicacão, o consumo e o crime na juventude, a partir da pergunta: é possível haver conexão entre o discurso midiático (direto ou subliminar) - o conjunto de narrativas jornalísticas, publicitárias e de entretenimento sobre o consumo e o uso de bens - e a construção da identidade dos jovens, conduzindo alguns deles às ações criminosas como forma de posse desses objetos? A compreensão da dimensão cultural do ato criminoso como meio de acesso aos bens surge através da interface de estudos acerca do consumo, da juventude e do crime.

Palavras-CHAvE: Cultura de consumo. Mídia. Significante e significado. Juventude. Crime.
\end{abstract}

\section{INTRODUÇÃO}

Estudos clássicos e contemporâneos sobre os meios de comunicação ressaltam a influência que a mídia exerce no desenvolvimento de crenças e atitudes dos indivíduos. Quando pensamos em discursos midiáticos - as narrativas jornalísticas, publicitárias e de entretenimento -, percebemos como é possível propor revisão de conceitos e novas significações para os fatos sociais a partir dessas narrativas. A exposição à mídia tem um relevante papel de interferir nas formas de ver e pensar acerca das coisas do mundo, operando tanto sobre a dimensão objetiva quanto subjetiva do ator. De um modo geral, os indivíduos são vulneráveis ao processo persuasivo das narrativas midiáticas porque suas posições são de observadores lenientes de uma persistente publicidade que define comporta-

*Doutora em sociologia. Pesquisadora da Fundação Joaquim Nabuco.

Rua Dois Irmãos, 92 . Fundaj/Campus Anízio Teixeira. Cep: 52.071-440. Apipucos - Recife - Pernambuco Brasil.patricia.melo@fundaj.gov.br

** Mestrando em sociologia. Membro e assistente de pesquisa do Núcleo de Pesquisas Sociofilo (IESP-UERJ). rodrigo_assis@iesp.uerj.br mentos aceitáveis, condições de distinção social e elementos que se incorporam aos indivíduos, dando sentido às suas identidades na estrutura social. Além disso, as representações midiáticas assumem papel ativo de controle social, estabilidade e mudança, mostrando - na narrativa jornalística, de telenovela, fílmica ou de entretenimento - as várias versões do ser indivíduo-em-busca-de-distinção: pelo carro, pelas roupas, pelo corpo, pelos objetos vinculados a esse ser.

Fechamos nosso debate ao grupo definido como jovens, para os quais a psicologia estabelece um estado diferenciado de vulnerabilidade em virtude dos específicos processos de socialização nos quais suas identidades são produzidas paralelamente às alterações hormonais biologicamente determinadas. Ainda que Bourdieu (1983) questione o sentido de juventude, estabelecendo-o como uma construção social, Lahire (2006) fala da juventude como etapa da vida, fase situada entre a irresponsabilidade dos atos infantis e a responsabilidade da vida adulta. É o momento de constituição de valores e busca de reconhecimento nos inúmeros campos sociais nos quais esses indiví- 
duos circulam. Está dada aí a condição de vulnerabilidade dos jovens, eé sobre eles que lançamos nosso estudo, com o intuito de pensar em que medida as narrativas midiáticas estabelecem a posição social dos indivíduos e sua condição de felicidade e de reconhecimento no grupo, atrelada, ao que possuem: celular, carro, roupas de marca etc.

Tanto no jornalismo como na publicidade, indivíduos-referente ${ }^{1}$ - como atores, autoridades econômicas e políticas, mulheres bonitas, homens elegantes - informam sobre questões sérias, como saúde, economia, educação, misturados às significações sobre vestir-se, portar-se, ter, numa posição de credibilidade sustentada pela mídia. Anunciam também qual a senha de entrada para adquirir distinção e ascender àquela posição social. Ter certos objetos, vestir determinadas roupas e frequentar ambientes específicos vão dizer a que grupo social o indivíduo pertence (Bourdieu, 2008). A comunicação é estrutura para o consumo do público, e o público a recebe como sentido a ser incorporado à sua identidade, ao seu ser no mundo.

No contexto do capitalismo atual, do qual os meios de comunicação são parte como conglomerados industriais transnacionais, o espectador de rádio e TV e o leitor de jornal ou internet são categorizados como consumidores. Notícia é um produto a se consumir, uma mercadoria à venda. Assim, publicidade e jornalismo se confundem e convergem, produzindo sentidos focados no estí-

${ }^{1} \mathrm{O}$ referente é um objeto significante que se refere ao outro, mas é também um significado, um signo, uma expectativa interna. Segundo Saussure (2006), essa relação - significante-significado - é arbitrária, é uma construção social. Ao elaborar sua linguística estruturalista, Saussure destaca que os sentidos são gerados segundo a relação entre sons e conceitos. O signo - como forma que faz referência a uma realidade ou a um objeto - é definido de modo arbitrário, e seu sentido, o seu valor, são definidos nesse mesmo caminho. A cada signo corresponde um significante, a coisa-em-si representada e significado(s), sentido(s), a ela arbitrados. Um significante - a coisa-em-si - pode remeter a vários significados, uma vez que vários sentidos podem ser acessados. Nesse caminho, o indivíduo-referente é o ponto ótimo da significação, a expectativa de cada um para o alcance de distinção social (Bourdieu, 2008), uma espécie de tipo ideal. Consequentemente, o referente é "[...] o objeto particular a que a palavra corresponde no caso concreto da circunstância ou do uso" (Benveniste, 1989, p. 231). Assim, o significado é o pensamento, e o referente, por seu turno, é a percepção produzida da realidade, a representação que se faz dela. Em suma, como parte fenomenal do signo, os indivíduos-referente indicam como o mundo deve ser visto, interpretado e vivido. mulo à compra de bens anunciados em tempo integral, direta ou subliminarmente. Para Barak (1994), a mídia está subordinada aos valores hegemônicos da economia política. Se a senha de entrada é a posse de bens determinados no discurso midiático dominante, os indivíduos empenham-se em adquirir esses bens. Embora o desejo de consumo impregne os indivíduos indistintamente, a aquisição de bens pressupõe recursos financeiros; logo, sua posse é definida pelo poder de compra.

Ainda que os meios de comunicação sejam instrumento de orientação e tendência em inúmeras direções, sua condição de pertencimento à estrutura econômica os faz espaço de mediação para o estímulo ao consumo necessário à manutenção do modelo capitalista. A mídia, aliás, é exemplo das contradições do capitalismo: espaço de debate e crítica da sociedade, ela integra o mesmo sistema na forma de conglomerados dominados por grupos empresariais. Assim, Barak (1994, p.241) liga "[...] a produção da mídia ao grande aparato ideológico da sociedade capitalista".

Por essa razão, programas infantis e juvenis são intercalados com publicidade de brinquedos, roupas, sapatos e até de alimentos, focados nesses grupos. Num contexto de formação de identidades, esse discurso reforça as relações de privilégio e desigualdade, sustentando que somente se tem sentido - o indivíduo - quando se pode dispor de bens que o posicionem ou o façam circular em determinados campos sociais. Significante e significado - indivíduo e indivíduo-portador-de-objetos-definidores-dedistinção - são partes da relação entre valor de uso e valor de troca $(\mathrm{VU} / \mathrm{VT})^{2}$ da economia política.

\section{CULTURA DE CONSUMO: debate necessário}

Muitas vezes, as práticas de consumo são consideradas como atividades básicas da vida, dando um caráter de supressão de necessidades

${ }^{2} \mathrm{Na}$ concepção marxista, o valor de uso (VU) se constitui na decodificação racional, no conteúdo material da riqueza, pressupondo objetividade e utilidade do bem. O valor de troca (VT) é o discurso da comunicação, uma abstração (Marx, 1988). 
biológicas da natureza humana. Também são desenvolvidos argumentos em favor da frivolidade do ato de apropriação de bens. É preciso compreender o que dá sentido às práticas de consumo no mundo contemporâneo e qual o valor social atribuído ao sucesso dessa prática. Se o objetivo deste artigo é articular teoricamente o crime, o consumo e a juventude, é preciso articular a relação entre consumo e criminalidade no contexto dos jovens, traçando um limite do que se entende por cultura de consumo.

Nas sociedades contemporâneas, o consumo e os modos de execução das formas de apropriação dos bens classificam e qualificam a posição social dos indivíduos no espaço social. Nesse sentido, a concepção de cidadão se confunde com a concepção de consumidor: quem não possui recursos para efetivar os atos de consumo sente-se excluído da estrutura social, alheio ao mundo dos direitos sociais e individuais, o que desemboca em uma redução da ideia de cidadania e também em uma vinculação de que a existência social depende da constante renovação dos bens (Canclini, 1999; Rocha, 2011). Mas, afinal, por que são dados a alguns os meios para consumir e a outros não? Isso é uma questão controversa, que ajuda a adentrar na compreensão da apropriação ilícita de objetos como uma forma de definir qual o espaço do indivíduo no mundo. Numa perspectiva de cultura determinante da estrutura social, a posição do jovem, ao apropriar-se de bens, pode se configurar num ato rebelde, para negociar seu acesso ao consumo. Como dizem Ferrell et al (2008), cultura não é um substantivo, mas um verbo e, como tal, assume tempos passivos e ativos:

Cultura sugere uma espécie de performance pública compartilhada, um processo de negociação pública - em que o desempenho pode ser aquiescência ou rebelião, uma negociação de conflitos violentos ou capitulação (2008, p. 4) [tradução nossa].

As identidades contemporâneas são definidas peloconsumo, queéanunciado publicitariamente como o meio para o alcance da igualdade e da liberdade, mas esse discurso deixa uma lacuna acer- ca dos excluídos desse processo, aqueles a quem não é dado o direito ao consumo pela inexistência de poder de compra. Enquanto isso, as mercadorias são exibidas como competentes portadoras de uma aura legitimadora de distinção. Após a aquisição do objeto, porém, essa aura se desintegra, exigindo do consumidor o retorno ao mercado e a uma nova compra para a recuperação de nova aura para aplacar a incessante busca por distinção (Campos; Souza, 2003). Como diz Leite (2011, p.2), “[...] fomos acostumados a comprar para consumir não a coisa em si, mas sua promessa de plenitude e felicidade".

No século XXI, a identificação das pessoas com a noção de consumidores se processa no cerne de um contexto em que ao exercício da cidadania é atribuído um sentido voltado para o espaço da vida privada e para os interesses individuais. Em grande medida, isso decorre do fato de que a democracia, tomada de forma abstrata, e a desigual inclusão social dos indivíduos nos espaços públicos de participação política se apresentaram em conjunto com a difusão de valores capitalistas que alimentam o crescimento do campo de atuação dos meios de comunicação e operam como difusores das dimensões estéticas que legitimam determinadas maneiras de ser, ou estilos de vida - distintivos-modernos.

No pensamento sociológico, a perspectiva teórica que primeiro sinalizou a discussão sobre o consumo foi o marxismo. Em Marx, o consumo é colocado no interior da lógica da produção. Ele estava mais interessado em identificar e analisar a reprodução do capital do que investigar o consumo final das mercadorias. Segundo Taschner (2009, p.51-52), Marx aponta que o consumo, mesmo determinado pela produção, "[...] é um momento que tem seus desdobramentos e condicionantes". A autora evidencia um pensamento importante de Marx (apud Taschner, 2009, p. 52), fundamental para pensar o consumo:

O objeto [... de consumo ...] não é um objeto geral, mas um objeto determinado, que deve ser consumido de forma determinada, à qual a própria produção deve servir de intermediário. A fome é a fome, mas a fome que se satisfaz com carne 
cozinhada, comida com faca e garfo, não é a mesma fome que come a carne crua, servindo-se das mãos, das unhas, dos dentes.

Desse modo, indo além do olhar materialista sobre o mundo social, o marxismo dá margem para se pensar a dinâmica da subjetividade, dos valores e dos significados inscritos nas práticas de consumo. Podemos entender que o consumo não é apenas um elemento contido no processo de produção e reprodução de capital; é preciso escapar da dimensão que privilegia o econômico e se pensar em outros níveis da experiência da vida social. As práticas de consumo são marcadas pela estrutura simbólica compartilhada de um tempo, estão preenchidas pelos valores legitimados de um momento histórico e com eles se modificam.

Ainda na perspectiva marxista, Adorno e Horkheimer (2002), ao elaborar o conceito de indústria cultural, desenvolvem uma crítica ao sistema capitalista de produção. No caso do estudo acerca da comunicação de massa, esse sistema é percebido como meio pelo qual a esfera da cultura adentrou em uma lógica de produção cumulativa, utilizando-se da técnica para reprodução, em larga escala, de bens culturais (Benjamin, 1982).

A cultura, no sentido antropológico, tem um peso determinante sobre o sentido e a forma do consumo e deve ser levada em consideração ao se buscar desvendar os significados sociais atribuídos aos atos de apropriação dos bens. Desse modo, na medida em que à cultura é delegado um papel estruturante sobre os indivíduos e sobre suas ações, verificamos um caminho para se pensar a cultura de consumo (Featherstone, 1995; Rocha, 2002; Taschner, 2009). Ao olhar o consumo para além de uma determinação da produção das mercadorias, considerando "[...] sua própria problemática e seus efeitos sobre a totalidade social [...]", é que se pode pensar a emergência de uma cultura de consumo (Taschner, 2009, p. 52).

Com a Revolução Industrial, cai o preço dos produtos, mas é preciso considerar que o consumo não se daria apenas pelo fato de existirem bens a custos acessíveis. Era preciso haver indivíduos dispostos a consumi-los. Nessa lógica, Taschner
(2009) busca as origens e as possíveis raízes extraeconômicas da cultura de consumo e tem o mérito de desenvolver uma análise que põe o consumo em uma lógica que articula os níveis social, cultural e político da vida coletiva, para explicar o surgimento de hábitos - e seus sentidos - de apropriação de bens.

McCracken (1990 apud Taschner, 2009) aponta uma mudança no padrão de consumo. Ao padrão tradicional de consumo da corte ele chama de consumo de pátina, advindo do período medieval, no qual se destacava a família como singularidade do consumo. Seria o meio de legitimação do nome da família pelas heranças e riquezas acumuladas através de gerações. A mudança no padrão de consumo identificada por McCracken ocorre quando os indivíduos passam a consumir para si mesmos, e não para o acúmulo de riqueza e prestígio familiar. Era um momento de ascensão do individualismo. Nesse terreno, a atribuição de valor aos bens começou a ganhar ar de modernidade: não apenas os bens familiares tinham relevância social, mas a novidade, a aquisição de algo novo passou a ocupar um lugar que antes não era admissível.

Ao traçar uma breve conceituação sobre cultura de consumo, Rocha (2002) afirma que a dimensão da moda pode ser entendida como um dos princípios básicos dos modos de consumo na modernidade. Há uma oposição subjetiva e material à lógica do consumo de pátina, identificado em McCracken, uma inversão de sentido do privilégio: o antigo, a tradição e o consumo para status familiar são desprestigiados; o novo, a inovação e a aquisição recente ganham relevância social.

O desenvolvimento do campo da moda possibilitou uma aproximação de outras camadas da sociedade às mercadorias. Mesmo com a perda do poder das cortes reais, após as Revoluções Burguesa e Industrial, os indivíduos-referente no campo do consumo pertenciam àquelas famílias abastadas. Mas, agora, havia a possibilidade de o indivíduo de outras classes mover-se na estrutura social, gozando da representação de si no espaço dos estilos de vida (Bourdieu, 2008).

Na contemporaneidade, é comum “[...] nos 
sentirmos convocados como consumidores ainda quando se nos interpelam como cidadãos" (Canclini, 1999, p. 14). A nosso ver, grande parte dessa imbricação de sentidos fortaleceu-se a partir das narrativas midiáticas, utilizadas para difundir os valores que dão forma à dinâmica capitalista. Desse modo:

As lutas de gerações a respeito do necessário e do desejável mostram outro modo de estabelecer as identidades e construir a nossa diferença. Vamos nos afastando da época em que as identidades se definiam por essências a-históricas: atualmente configuram-se no consumo, dependem daquilo que se possui, ou daquilo que se pode chegar a possuir (Canclini, 1999, p. 15).

O crime desenvolvido pelo desejo de consumo, motivado pela busca de distinção e pertencimento a determinados grupos, pode ter seu ponto de partida em um processo de socialização dos indivíduos que contém, em seu cerne, elementos derivados das produções que estimulam regularmente práticas de consumo, naturalizando-as como meio para exercer sua humanidade no mundo social capitalista. As práticas de consumo são vistas, assim, como parte do esforço em prol da mobilidade posicional no cerne da estrutura social. Há uma luta constante de significação das definições do que é necessário e do que é supérfluo na vida cotidiana, e o mercado de produção simbólica é o principal motor dessa luta.

Podemos afirmar que a busca por evidência no espaço social torna-se uma ação orientada para suprir as exigências do ego individualista e hedonista moderno, engendrado e reproduzido nos produtos veiculados pelos meios de comunicação (Melo, 2009; Taschner, 2009; Rocha, 2011). As pessoas, em especial os jovens (dentro de um processo de formação de identidade), estão mais vulneráveis à interpelação dos mecanismos de diferenciação social pautada pela representação dos indivíduos na mídia, atribuindo poder a quem detém bens considerados publicamente valiosos, gerando efeitos inesperados (Boudon, 1979; Merton, 1979) e reproduzindo dinâmicas sociais efetivadas pelo desejo de posse.
Tomando por base a discussão desenvolvida por Augras (1980), percebemos que os produtos midiáticos visam à persuasão. A autora considera haver um "[...] conjunto de técnicas que, valendo-se do conhecimento dos mecanismos psicológicos de formação das atitudes e opiniões, visa a utilizar tais mecanismos para obter atitudes e opiniões desejadas [...]" (1980, p. 67). Os meios de comunicação na estrutura social, nessa linha de pensamento, são mais do que meios para comunicar.

A propaganda vende estilos de vida, mercadorias que prometem a felicidade (Rocha, 2011). Com isso, dão significado à vida. Nessa lógica, o valor de uso do bem se atrela a seu valor de troca, numa relação simbólica, remetendo às identidades dos que podem ou não consumi-lo. Essa condição exprime e mascara as condições de produção para a economia política: a separação entre significante e significado, no nível do signo, ou entre infraestrutura (base econômica) e superestrutura (classe dominante), no nível da produção da mercadoria. Cultura e signo não estão separados; são ligados por significados dados ao referente pela cultura (Baudrillard, 1973). ${ }^{3}$

No consumo, a mercadoria é produzida como signo, e o signo como mercadoria. É no interior dessa relação que se encontra a cultura. O efeito de sentido é de que as necessidades escamoteadas são expostas como o VU do bem, quando são, na verdade, o seu VT. O valor de troca é dissimulado, escondido, tendo o valor de uso como álibi. No sistema da economia política, a ambivalência simbólica é reduzida e é estabelecida a equivalência entre os valores (Baudrillard, 1973). E, quando se naturaliza o sentido de posse do bem como fundamental para definição da identidade, não se vê

${ }^{3}$ Em trabalho posterior, Baudrillard (1996, p.9) avança nessa discussão, problematizando mais a questão do valor, ao afirmar que "[...] cada configuração do valor é reavaliada pela seguinte numa ordem de simulacro superior. E cada fase do valor integra ao seu dispositivo o dispositivo anterior como referência fantasma, referência fantoche, referência de simulação". Com isso, a manipulação é generalizada, pois o sentido entra num círculo infinito, e o arbitrário é tanto o significante quanto o significado. Não vamos, porém, ingressar nesse nível do pensamento braudrillardiano, pois ele reflete uma discussão sobre a qual não ingressamos neste artigo. 
o processo de mistificação do objeto ofertado no mercado, portador de uma "alma" capaz de dar sentido a quem o possui.

Se a indústria cultural pressupõe consumidores capazes de dispor de esforços e capitais para alcançar os produtos oferecidos para consumo, pressupõe-se também que, no universo dos produtos, existe uma lógica destinada a atender ao universo de consumidores potenciais em suas especificidades (Adorno; Horkheimer, 2002; Bourdieu, 2008; Canclini, 1999). É dessa forma que diferentes classes e frações de classe, na busca por mobilidade no mundo social, tendem a querer adquirir produtos que as distingam, engendrando práticas articuladas em uma dupla dimensão de sentido: inclusão e exclusão. É desse modo também que os jovens são levados a querer adquirir status pela via do consumo de bens considerados distintivos e que são, também, inclusivos em inúmeros campos sociais.

\section{CRIME E JUVENTUDE: um olhar a partir da proeminência da cultura}

As pesquisas de Alexander (1992, 1993), que fundamentaram a sociologia cultural, contribuíram para o desenvolvimento da criminologia cultural, ao apontar em que medida a cultura é determinante da estrutura social. Colocar a cultura nessa posição é a chave para entender duas questões relevantes: a cultura de consumo e a cultura do crime. Neste tópico, vamos abordar a cultura do crime.

Pesquisas realizadas no início do século passado contribuíram para os estudos sobre o crime, especialmente as formas de adaptação dos indivíduos às normas sociais e às práticas desviantes. A definição legal de crime é conjunturalmente cultural, muitas vezes resultando das pressões sociais - as atitudes inovadoras e rebeldes. Assim, antes de estar na lei, o crime precisa adquirir um sentido social, coletivo, modificado na medida em que a sensibilidade humana, numa sociedade, se altera diante dos fenômenos sociais e dos seus valores mutáveis.

Frente à pergunta "o que é um ato crimino- so?", é preciso que nos coloquemos em posição crítica sobre o estabelecimento de conceitos. O sentido atribuído a uma ação está inscrito no tempo e na história. O significado do crime não está colado no ato em si, marcado pelo contexto, mas vem atrelado aos valores circulantes. Logo, o conceito não é o fato em si, porque os valores, que se alteram ao longo da história, contribuem para a mudança da definição do ato (Melo, 2010).

Pressupõe-se que as ideias que fundamentam a constituição de uma ação como um ato criminoso devem resultar de premissas que evidenciem que ações são dotadas de um sentido social de crime. A relação entre significante e significado tem, muitas vezes, como esteio a utilidade de considerar esta ou aquela ação criminosa e o resultado do ato como mal para a coletividade. Nessa lógica, o conceito de crime se altera ao longo da história, para dar conta do refinamento da sensibilidade humana acerca dos fenômenos sociais, ou seja, em decorrência dos valores (mutáveis) dos indivíduos (Tonry, 2004; Foucault, 2006; Melo, 2010).

A variável cultural é responsável pelos sentidos atribuídos às ações humanas. A estrutura cultural, dando sentido às forças sociais, interfere e dirige as significações que convencionam os fatos sociais e, entre eles, o crime. Merton (1970, p. 236-237) define a estrutura cultural como "[...] o conjunto de valores normativos que governam a conduta comum dos membros de uma determinada sociedade ou grupo". Segundo ele, a anomia é

[...] uma ruptura na estrutura cultural, ocorrendo, particularmente, quando há uma disjunção aguda entre as normas e metas culturais e as capacidades socialmente estruturadas dos membros do grupo em agir de acordo com as primeiras.

Uma compreensão clássica de crime é a de qualquer comportamento desviante do estabelecido pelo senso comum como normal, no tempo e no espaço, que atinja a moralidade coletiva e produza um ultraje moral nos indivíduos. A definição das leis não é suficiente para explicar todas as ações humanas que se constituem em desvio e, muitas vezes, as alterações legais resultam de pres- 
são social em decorrência de surtos de pânico que fomentam mudanças para atender a esses clamores, sem que se tenha comprovação de que realmente a modificação se faz necessária. Por exemplo, nos casos de crimes violentos praticados por jovens, suscita-se uma discussão sobre a redução da maioridade penal como solução para reduzir os crimes cometidos por adolescentes (Melo, 2010). Merton (1970, p. 237) acrescenta que:

A estrutura social age como barreira ou como porta aberta para o desempenho dos mandatos culturais. Quando as estruturas social e cultural estão mal integradas, a primeira exigindo um comportamento que a outra dificulta, há uma tensão rumo ao rompimento das normas ou ao seu completo desprezo.

A tensão entre a cultura e a estrutura social pode ser remetida à concepção da sociologia cultural sobre a autonomia relativa da cultura e sua capacidade de determinar as relações sociais (Alexander; Smith, 2002; Kane, 1991). No caso do crime, o sentido é elaborado a partir de uma codificação simbólica, na qual estão contidos valores que subjugam a conduta dos indivíduos. Se os indivíduos rompem com esses valores, está aí instalada a condição desviante de seus atos.

O crime violento é um fato social e cultural. Se uma determinada sociedade cobra dos seus indivíduos grandes realizações para a conquista de uma posição de distinção, é provável que nela haja um grande número de comportamentos desviados, frustrados por não alcançarem o êxito exigido. Dessa forma, é a cultura que delimita os objetivos e substabelece o comportamento do indivíduo, podendo estimular atos delituosos, com ou sem violência associada a eles, o que nos permite vincular a ideia de autonomia relativa da cultura sobre a estrutura social (Alexander; Smith, 2002; Kane, 1991), sendo, nessas circunstâncias, a provocadora da situação anômica.

Nessa relação de causalidade entre cultura e estrutura social, a anomia pode ser a causa do crime, sendo a anomia, como dito anteriormente, a tensão entre os objetivos culturais e as oportunidades para atingi-los, ou seja, a desorganização social (Merton, 1970), sejam tais objetivos de ordem econômica ou não. Na lógica mertoniana, a estrutura social que não dispuser desses dois níveis altamente integrados - objetivos culturais de êxito e meios institucionais para alcançá-los - está em condições anômicas e tem mais chances de ter uma sociedade com índices mais elevados de criminalidade. Merton (1970, p.209) ressalta a importância do dinheiro e sua condição de ser um “[...] símbolo de prestígio [...], não importando como adquiri-lo, fraudulenta ou dentro das instituições [...]”. Ele diz:

A cultura pode ser tal que induza os indivíduos a centralizarem suas convicções emocionais sobre o complexo de fins culturalmente aplaudidos, com muito menos apoio emocional sobre os métodos prescritos para alcançarem essas finalidades (1970, p. 207).

As pesquisas iniciais que formaram a base da criminologia cultural (abordando questões sobre cultura, subcultura e poder) ajudaram a estudar especialmente as formas de adaptação dos indivíduos às normas sociais e às práticas desviantes. Algumas estruturas sociais fazem pressões sobre os indivíduos, estimulando-os a comportamentos não conformistas (Magalhães, 2004). Atitudes definidas como conformidade, inovação, retraimento e rebelião foram classificadas por Merton (1970) e englobam os modos pelos quais os indivíduos se comportam diante das regras. Esses modos de adaptação são estendidos aos estudos sobre as tradições da juventude, quando é qualificada a delinquência, o radicalismo e a boemia como reações juvenis (Matza, 1968).

Segundo Matza (1968), as três modalidades de reações juvenis têm implicações distintas. Ele caracteriza cada grupo de jovens da seguinte forma: (i) radicais - têm consciência de sua intelectualidade, são críticos e desejam reformar a sociedade; (ii) delinquentes - não têm planos para a sociedade, não desejam reconstruí-la; e (iii) boêmios - estão numa situação intermediária, são refratários, mas convencidos, como os radicais, do valor moral do movimento em que se inserem.

A conformidade é uma atitude de manuten- 
ção de acordo tanto com os objetivos culturais de uma estrutura social como com os meios institucionais para atingi-los. A atitude inovadora pode ou não se constituir em crime, pois é uma transação que vai além dos costumes estabelecidos, mas que, muitas vezes, encobre crimes e fraudes. O ritualismo pressupõe seguir regras, mas os indivíduos perderam as esperanças de atingir objetivos pressupostos pela sociedade (estudar, "ser alguém na vida”). Na rebelião, há uma busca por uma nova ordem estrutural, enfrentando a ordem vigente (luta pela descriminalização do aborto, pela liberação da maconha). O retraimento é a adaptação pela apatia, o alheamento social.

Embora polêmico, há teóricos que abordam a sedução do crime e a experiência sensual dos atos criminosos para os indivíduos. Katz (1988, p.4) critica a raridade de estudos em sociologia e psicologia que abordem o prazer da prática criminosa, ressaltando que alguns indivíduos veem um apelo sedutor no crime, uma dinâmica atraente que compele à ação criminosa. "Quando eles estão cometendo crimes, sentem-se atraídos e impulsionados, num sentimento determinado por forças externas".

Superando o olhar que relacionava a prática criminosa à condição social de pobreza, Zaluar (2004) percebe arranjos complexos em que a cultura e os sentidos das ações dos indivíduos se articulam com base no prazer do sucesso dos objetivos das práticas. Na especificidade do contexto social brasileiro, contudo, percebe-se, nas relações em que a figura masculina é tratada como detentora legítima de poder e de protagonismo, um ponto-chave dessa discussão:

A repetição de certos arranjos e associações simbólicas relacionando o uso da arma de fogo, o dinheiro no bolso, a conquista das mulheres, o enfrentamento da morte e a concepção de um indivíduo completamente autônomo permitia vincular a violência a um etos de masculinidade, que posteriormente considerei um etos guerreiro, tal como exposto por Norbert Elias (Zaluar, 2004, p. 237).

Isso significa que, na tensão entre o indivíduo e o sistema social em que se socializou, a op- ção pelo crime surge como uma alternativa que não é necessariamente dolorosa para quem a pratica, ou seja, pode conter prazer. Assim, seja por uma compulsão estimulada pela mídia para o consumo (estrutura), seja por uma opção pela prática criminosa como uma escolha sensual (agência), o crime não é, para todos, algo percebido como um mal em sua totalidade (Katz, 1988).

O ganho teórico ofertado pela criminologia cultural é de poder dissolver sentidos convencionais do crime, pensando a questão em termos urbanos, midiáticos, antropológicos e as práticas sociais como formas de intervenção sobre esses sentidos. A criminologia cultural funda uma teoria que navega na modernidade tardia, buscando entender as condições contemporâneas que confrontam um novo mundo de crimes e controle social, o papel das mediações na constituição do sentido de crime, os sentidos em fluxo, as exclusões sociais. Vejamos o seguinte:

Nos anos 40, um homem poderia frequentemente bater numa mulher na boca e isto significaria... Bem, nada demais. A violência doméstica ainda não tinha sido inventada como uma categoria legal e cultural (eis a palavra de novo) -e isso não tinha sido definido amplamente, reconhecido e condenado como um tipo específico de comportamento criminoso. Foi preciso a ação do movimento feminista e décadas de ativismo político para chegar a este ponto (Ferrell et al., 2008, p.8) [tradução nossa].

Muitos dos atos criminosos entram na agenda midiática como tendências nacionais ou reações de subculturas juvenis - como ocorreu em 2011 no ataque a uma escola pública do Realengo, no Rio de Janeiro. Muitos defendem que essa violência "gratuita" - em contraposição a uma violência legitimada pelo Estado - não é fruto das desigualdades que frustram a realização de objetivos culturais, transcendendo as questões socioeconômicas.

Entretanto, Ferrell et al. (2008) argumentam que essa violência está, sim, entrelaçada às condições de exclusão de camadas sociais que não estão no mercado reconhecido de trabalho ou no sistema de educação. Eles dizem que essa é uma “[...] cultura contemporânea mesquinha de agressão 
comercializada e uma sensação permanente de masculinidade definida pelo machismo, violência e dominação[...]” (2008, p.10).

A globalização, os conflitos globais, o capitalismo e a crise econômica mundial, a mídia globalizada, as incertezas, as formas plurais da ação criminosa e as justificativas para as punições constituem o quadro atual dos estudos da criminalidade. O crime entra no espetáculo público, pois as experiências das vítimas são publicizadas, as punições são festejadas, tudo compartilhado midiaticamente com a coletividade, que comparte a dor do outro todos os dias.

Se pensarmos em termos de sociedade brasileira, a ênfase no sucesso, na ambição e no consumo - especialmente através da mídia, em programas jornalísticos, publicitários e de entretenimento, como telenovelas - está em desacordo com as possibilidades da maioria dos indivíduos de acesso aos meios aprovados para conquista dessas metas. O estímulo midiático talvez possa explicar, em parte, o crime associado à intenção de obter ganhos, inclusive para garantir o consumo.

Fundamental é, porém, destacar que a prática do crime - com foco ou não no consumo não pode ser associada às condições econômicas exclusivamente, porque os atos criminosos estão presentes nos vários estratos sociais. O apelo sedutor do crime sobre o qual nos fala Katz (1988) atinge todos os indivíduos, e alguns - de qualquer classe social - se sentem compelidos à prática.

Em nossa discussão, a cultura de consumo é o canto da sereia presente na mídia, e aqueles que não têm poder de compra podem ou não ser seduzidos por ele. A condição de vulnerabilidade dos jovens é que os coloca numa posição de risco. É claro que a cada ação criminosa há condições individuais que determinam o ato, mas aqui estamos atentos às determinações estruturais, pois as condições subjetivas ingressam no exercício da pesquisa empírica, que não é nosso objetivo neste artigo.

\section{OS JOVENS E A PRÁTICA CRIMINOSA PARA O CONSUMO}

Acreditar que alguns jovens admitam práticas ilícitas para consumir pode parecer difícil, mas Leite e Brenneisen (2011, p. 13) conseguiram isso, ainda que sua pesquisa não tivesse essa intenção. Eles afirmam que a busca de recursos para o lazer e o consumo é um esforço frequente dos jovens, que admitem adotar "maneiras ilícitas para conseguir dinheiro”. Leite e Brenneisen (p.14) afirmam que não questionaram que atividades ilegais eram praticadas para não comprometer o seu estudo. E afirmam: “[...] o que importa destacar é que, de ambas as maneiras, lícitas ou ilícitas, os jovens acompanhados despendem a maior parte de seus ganhos financeiros com moda/indumentária [...]”.

Martín-Barbero (1997, p. 290) sintetiza a relação entre os meios de comunicação, o consumo e as práticas sociais expressas na vida cotidiana ao destacar que:

O espaço de reflexão sobre o consumo é o espaço das práticas cotidianas enquanto lugar de interiorização muda da desigualdade social, desde a relação com o próprio corpo até o uso do tempo, o habitat e a consciência do possível para cada vida, do alcançável e do inatingível. Mas também enquanto lugar de impugnação desses limites e expressão dos desejos, subversão de códigos e movimentos da pulsão e do gozo. O consumo não é apenas reprodução das forças, mas também produção de sentidos: lugar de uma luta que não se restringe à posse dos objetos, pois passa ainda mais decisivamente pelos usos que lhes dão forma social e nos quais se inscrevem demandas e dispositivos de ação provenientes de diversas competências culturais.

Martín-Barbero (1997) abre margem para uma reflexão sobre o universo social do crime acionado pelo desejo de consumo entre jovens. Há, sim, uma atribuição de sentido social ao uso de determinados bens, expostos pela indústria cultural. Esse sentido passa pela diferenciação social via práticas de distinção, que está diretamente associada ao ato de possuir, de consumir, de ter. O desejo pelos produtos pode ser controlado, mediante organização de "competências culturais" que indi- 
cam o caminho legítimo para aquisição de bens, obedecendo a normas sociais e legais. No entanto, da mesma forma que existe desigualdade econômica, também existe desigualdade em níveis de competências culturais, fazendo surgir práticas desviantes de subtração de bens, o crime motivado pelo desejo de consumo.

Taschner (2009, p.90) também possibilita relacionar o estudo sobre a cultura de consumo e ações criminosas quando afirma que "[...] há muita gente excluída do lazer e de muitas formas de consumo, apesar de participar da cultura do consumo [...]”. Todos os indivíduos estão sujeitos à interpelação das representações produzidas e reproduzidas nos meios de comunicação e, na medida em que se interiorizam os sentidos e traços de distinção pelo consumo, as práticas objetivas dos indivíduos no mundo social são repensadas, transformadas e adaptadas para que se alcancem os valores vinculados à cultura de consumo. No processo de exteriorização dos valores apropriados, configura-se o indivíduo-portador-de-objetos-definidores-de-distinção: um sujeito distinguido em si mesmo e detentor de poder, adequado ao modelo de indivíduo-referente.

Desse modo, a cultura de consumo possui uma amplitude maior, que pode ser percebida $a$ priori. Ela está presente nos variados domínios da vida social. Por exemplo, as práticas de lazer na modernidade, em grande medida, estão vinculadas a espaços de consumo (Taschner, 2009). Na execução das práticas, o próprio sentido do lazer se transmuta em princípio para a distinção social. Destacando a relação entre lazer e consumo, Taschner afirma que é possível, no contexto contemporâneo da cultura de consumo, verificar estratégias para adquirir o que se pretende possuir:

Em países mais ricos, o casamento entre lazer e consumo tende a durar - customizado em massa, virtual, culturalmente orientado - entre as camadas ricas e entre aquelas que têm um emprego ou seu próprio negócio ou que são trabalhadores autônomos. Ali se podem encontrar nichos, onde o consumo de lazer se direcione menos a produtos tangíveis e, mais e mais, ao consumo de sensações [...] Em outros segmentos, que são e - ao que tudo indica - podem permanecer particularmente abundantes em países do Terceiro Mundo, estamos propensos a encontrar camadas de baixa renda ou sem emprego que não têm acesso significativo ao mercado real de consumo - especialmente consumo de lazer - apesar de participarem da cultura do consumo (por exemplo: o office boy brasileiro que usa um tênis Nike, comprado a prestação, e o pivete que o obtém através do roubo) (Taschner, 2009, p. 90-91).

Isso indica que o crime pode surgir como rota de acesso aos bens que se quer possuir e ostentar. O sentido social dos objetos é valorado via representações difundidas na mídia e variam de acordo com a hierarquia socialmente constituída sobre cada bem em seu campo específico de utilização: transgredir regras sociais e legais ganha relevância nas escolhas dos indivíduos na medida em que a mercadoria que se pretende adquirir detém alto valor de troca, mesmo que não detenha alto valor de uso.

Em nossa discussão, a aquisição de certos bens via ação criminosa está mais próxima de uma distinção por exposição de (falso) poder de compra (pela posse ilegal) do que pelo poder de interiorização de capitais simbólicos. Isso não quer dizer que a pobreza motive o crime, mas que os jovens socializados numa sociedade contemporânea de consumo e com baixo poder aquisitivo (numa estrutura socioeconômica), tensionados pelo desejo de posse de determinados bens (numa estrutura cultural de consumo) poderiam estar mais vulneráveis para ingressar na criminalidade. O ato criminoso aqui é percebido como forma rápida de acesso ao que se quer adquirir: os meios (ilegais) para o alcance dos objetivos preconizados por Merton (1970).

Pressupomos que o etos de masculinidade seja, de forma significativa, estimulado e reproduzido pelos produtos da indústria cultural, na medida em que há uma via de mão dupla na elaboração do que vai ser ofertado ao público. Segundo Leite e Brenneisen (2011), a moda é uma afirmação de identidade para o jovem, conforme relato de um dos seus entrevistados:

Andar arrumadinho é muito massa, até pra sair mesmo, agarrar as guria, as gurias veem que você tá com roupa de marca, corrente, tênis legal, tá 
arrumadinho, é mais fácil chegar nelas e ficar com elas do que os outros que não estão com roupas de marca [...] (Erick, 20 anos, apud Leite; Brenneisen, 2011, p.16).

A indústria cultural objetiva alcançar aceitabilidade do público e, ao mesmo tempo, impõe padrões estéticos e estilos específicos de mercadorias ao indivíduo. É no campo das produções culturais (telenovela, filmes, música, jornalismo, publicidade e propaganda) que encontramos elementos que promovem a construção da imagem do indivíduo detentor de poder, de uma identidade social protagonista e de estilos de vida distintivos relacionados aos indivíduos-referente. O consumo, nesse contexto, é uma prática social marcada pelo sentido da distinção (Bourdieu, 2008).

A indústria cultural é capaz de expandir a dimensão imagética da relação com os bens (Rocha, 2002), representando e atribuindo sentido aos estilos de vida, estruturados hierarquicamente segundo a hierarquia social dos bens (Bourdieu, 2008). Atua, assim, como espaço de difusão e manutenção da própria estrutura de desigualdade das práticas cotidianas de consumo, legitimando certos grupos em detrimento de outros. Logo, introduz nos indivíduos, inclusive os situados em um contexto de vulnerabilidade social, uma disposição, entendida como habitus, ${ }^{4}$ marcada pela busca de sucesso e de prazer.

Embora nossa discussão busque uma congruência teórica que permita estimular pesquisas sobre o complexo relacional entre consumo, crime e juventude, alguns estudos empíricos sinalizam a relevância de nosso debate. Leite (2011, p. 1) aponta a afinidade temática ao narrar estudos com jovens moradores de periferias e afirma que a criminalidade está ligada "à avassaladora necessidade de consumo". Narrando um episódio do filme $A$ Ponte ${ }^{5}$, ela conta que uma pedagoga, ao pedir a um menino que deixe a criminalidade, ouve dele

${ }^{4}$ Entendemos habitus como um "[...] principio gerador de práticas objetivamente classificáveis e, ao mesmo tempo, sistema de classificação [...] de tais práticas [...]" (Bourdieu, 2008, p. 162). O habitus é um sistema de disposições duráveis que age em cada momento como esquemas de percepções e de ações.

${ }^{5}$ Filme de 2007 o seguinte: “[...] não me importo de morrer, tia ... Vou morrer com um ‘Nike’ no pé!”.

Leite (2011) vincula a cultura de consumo aos distúrbios anoréxicos, à prostituição infantil e às práticas criminosas. Ela enfatiza as condições reais de trabalho e de possibilidades de consumo, cuja senha de acesso é fornecida a poucos. Morrer com um "Nike" no pé nada mais é do que buscar no olhar do outro o reconhecimento, a certeza de que não se é fracassado. É melhor morrer na posse, sendo alguém, o indivíduo-portador-de-objetosdefinidores-de-distinção, numa tentativa de aproximação aos indivíduos-referente. Por isso, faz sentido pensar em jovens que optam pelo roubo, pelo tráfico e pelo furto para também gozarem nessa festa para a qual não foram convidados.

\section{CONSUMO, JUVENTUDE E CRIME: uma proposta de pesquisa}

A orientação da sociedade capitalista para o estímulo ao consumo sem controle parece construir um ideal de felicidade intrinsecamente atrelado ao dinheiro e à posse de bens (Rocha, 2011). A sociedade capitalista da informação modela um perfil de indivíduo cujo foco é o processo de distinção social pelo consumo e pelo alcance do prazer sem limites. Em nome de posição social e estilo de vida como elementos de seu capital simbólico, o indivíduo assume um habitus para garantir o sentido de pertencimento a um determinado grupo social (Melo, 2009).

Os meios de comunicação estão na raiz dessa cultura de consumo. Isso nos indica as condições de possibilidade de a mídia conduzir como causalidade negativa ou efeito perverso de sentido um indivíduo que, em nome do hedonismo, pode roubar ou se locupletar do lugar social que ocupa para deter mais recursos e poder ou de ocupação de espaços de distinção. Determinados tipos de consumo caracterizam a que campo social se pertence, pois é um processo de distinção que se estabelece na pós-modernidade, uma epidemia de consumo que nos parece difícil escapar. O estilo 
de vida é influenciado pelos meios de comunicação, que indicam como se vestir, o que possuir visivelmente para legitimar o seu lugar de fala (Melo, 2009).

O valor da riqueza é um símbolo de sucesso nas sociedades capitalistas. A cultura permeia todos os indivíduos de uma sociedade, mas é preciso considerar as diferenças idiossincráticas de suas histórias de vida. Assim, as reações, ou os modos de adaptação, vão resultar justamente da diferença de cada indivíduo e seu pertencimento a subgrupos diversos, que estão sujeitos aos estímulos culturais e às limitações estruturais de acesso para o alcance de objetivos de sucesso. $\mathrm{O}$ ponto de encontro entre o delinquente e a classe média, por exemplo, é, muitas vezes, a valorização do poder, dos bens e do dinheiro. Quem já tem dinheiro quer possuir objetos, ter prazer; quem não tem poder aquisitivo também está suscetível aos mesmos desejos.

O indivíduo é estimulado ao consumo para aparentar posição social. Quem quer ocupar esse lugar precisa vestir, usar o carro, ter celular, enfim, ostentar objetos que determinem sua posição, de onde olha para o outro e externa sua condição de distinção (Melo, 2010). O estilo de vida, os objetos ostentados em seu corpo são expostos na vitrine social. Para os que não podem materialmente consumir, é possível a posse à força. Como lembra Paixão (1988, p. 176) acerca do que diz DaMatta (1997), “[...] o quebra-quebra é o 'você sabe com quem está falando?' das massas de indivíduos destituídos e politicamente sem voz ou fórum [...]", uma forma de revelar o conflito e a crise do capitalismo. Nesses casos, o uso da rua funciona como arena política de embate em favor do direito ao consumo. Afinal, é a sociedade capitalista que vem anunciando que a cidadania é definida pelo acesso ao consumo.

O que podemos fazer acerca disso? Há múltiplas respostas e um desafio. O desafio é pôr em suspenso a ideia de que as causas da criminalidade do ocidente são fundamentadas pela lógica da estratégia de sobrevivência. Às causalidades múltiplas das práticas criminosas podemos acrescer elemen- tos psicossociológicos: o desejo de posse, de poder, de prazer e de distinção. Uma das possíveis respostas é o enfrentamento das políticas de comunicação, pensando formas de controle da produção da mídia em programas infanto-juvenis, quando o indivíduo está na fase primária de socialização.

Inúmeras pesquisas já apontam as relações entre infância, adolescência e a influência da mídia sobre as práticas de consumo (Campos; Souza, 2003; Bock et al., 2009; Taschner, 2011; Leite, 2011; Leite; Brenneisen, 2011). Como diz Taschner (2011), se já existe uma assimetria na relação entre produtores e consumidores adultos, essa assimetria ganha dimensões exponenciais quando o consumidor é criança ou adolescente. É verdade que, no processo de socialização, os jovens aprendem o que é a publicidade e qual a sua intenção, mas nem por isso deixam de ser influenciados por ela. Motivados à posse pelo impacto recorrente do discurso midiático, tais indivíduos partem para a ação: comprar o bem, pedir para que o comprem ou se apropriar dele.

As narrativas midiáticas estimuladoras do consumo - em suas variadas formas, do jornalismo à telenovela - integram a dinâmica capitalista atual, que exige liberdade em sua prática de anunciar bens associados a indivíduos-portadores-deobjetos-definidores-de-distinção (VU/VT). Pela repetição, a propaganda persuade o indivíduo, cada vez mais dissuadido de seus mecanismos de defesa. Faz sentido questionar essa prática, ao vislumbrarmos nela uma variável determinante - não a única, é verdade, mas uma variável relevante - do estímulo subliminar até mesmo de práticas ilícitas para a garantia de acesso ao consumo quando inexiste o poder de compra. Ilustra Galeano (2011), ao relatar a fala de um jovem argentino: “... quando não tens nada, pensas que não vales nada”.

Recebido para publicação em 30 de agosto de 2012 Aceito em 17 de março de 2013 


\section{REFERÊNCIAS}

ADORNO, T. W.; HORKHEIMER, M. Indústria cultural e sociedade. São Paulo: Paz e Terra, 2002.

ALEXANDER, J. C. The promise of a cultural sociology: technological discourse and the sacred and profane information machine. In: MÜNCH, R.; SMELSER, N.J. (Ed.) Theory of culture. Berkeley, Los Angeles: University of California Press, 1992.

et al. Risking enchantment: theory and method in cultural studies. In: Culture: the newsletter of the sociology of culture. v.8, n.1, p.10-14, 1993. Disponível em: research.yale. edu/ccs/alexander/articles/. Acesso em: 10 fev. 2012.

; SMITH, P. The strong program in cultural theory: elements of a structural hermeneutics. In: TURNER, H. (Org.) Handbook of sociological theory. New York: Kluwer Academics; Plenum Publishers, 2001. Disponível em: research.yale.edu/ccs/ alexander/articles. 2002. Acesso em: 08 fev. 2012.

AUGRAS, M. Persuasão e propaganda. In: $\mathrm{Opi-}$ nião pública: teoria e pesquisa. Petrópolis: Vozes, 1980. p.66-76.

BARAK, G. Media, process and the social construction of crime. New York, London: Garland, 1994.

BAUDRILLARD, J. O sistema dos objetos. São Paulo: Perspectiva, 1973

Para uma crítica à economia política do signo. Lisboa: Edições 70, 1995.

A troca simbólica e a morte. São Paulo: Loyola, 1996.

BENJAMIN, W. A obra de arte na época de sua reprodutibilidade técnica. In: LIMA, L. C. (Org.) Teoria da cultura de massa. São Paulo: Paz e Terra, 1982. p.209-240.

BENVENISTE, E. A forma e o sentido na linguagem. In: Problemas de linguística geral II. Campinas: Pontes/Unicamp, 1989. p. 220-242.

BOCK, A. B. et al. Mídia e psicologia: produção de subjetividade e coletividade. Brasília: Conselho Federal de Psicologia, 2009

BOUDON, R. Efeitos perversos e mudanca social. In: Efeitos perversos e ordem social. Rio de Janeiro: Zahar, 1979. p.17-55.

BOURDIEU, P. A “juventude” é apenas uma palavra. In: Questões de sociologia. Rio de Janeiro: Marco Zero, 1983. p.112-121.

A distinção - crítica social do julgamento. São Paulo: EDUSP; Porto Alegre: Zouk, 2008.

CAMPOS, C. C. G.; SOUZA, S. J. Mídia, cultura e constituição da subjetividade na infância. Revista Psicologia: Ciência e Profissão, Brasília, CFP, v.23, n.1, p.12-21, 2003.

CANCLINI, N. G. Consumidores e cidadãos: conflitos multiculturais da globalização. Rio de Janeiro: EDUFRJ, 1999.

DAMATTA, R. Carnavais, malandros e heróis: para uma sociologia do dilema brasileiro. Rio de Janeiro: Rocco, 1997. FEATHERSTONE, M. Cultura de consumo e pós-modernismo. São Paulo: Studio Nobel, 1995.

FERRELL, J. et al. Cultural criminology. London: Sage Publications, 2008.

FOUCAULT, M. Vigiar e punir: história da violência nas prisões. Petrópolis: Vozes, 2006.

GALEANO, E. O império do consumo. Disponível em: $<$ www.cartacapital.com.br >. Acesso em: 22 ago. 2011.
KANE, A. Cultural analysis in historical sociology: the analytic and concrete forms of the autonomy of culture. Sociological Theory, Los Angeles, University de California, v.9, n.1, spring, 1991

KATZ, J. Seductions of crime: moral and sensual attractions in doing evil. New York: BasicBooks, 1988.

LAHIRE, B. A juventude é apenas uma palavra: a vida sob tripla coação. In: LAHIRE, B. A Cultura dos indivíduos. Porto Alegre: Artmed, 2006. p.425-476.

LEITE, T. S. C. Criminalidade juvenil: uma estratégia de consumo. Disponível em: http://nucleotavola.com.br/revista. Acesso em: 15 set. 2011.

LEITE, T. P.; BRENNEISEN, E. Identidade juvenil e consumo de bens materiais: reflexões sobre uma área periférica de Paranaguá-PR. In: CONGRESSO INTERNACIONAL DA ASSOCIACÃO LATINO-AMERICANA DE SOCIOLOGIA, 22., 2011, Recife,. Anais... Recife: UFPE, 2011. MAGALHÃES, C. A. T. Estrutura social, cultura e criminalidade. In: Crime, sociologia e políticas públicas. Belo Horizonte: Newton Paiva, 2004. p.51-77.

MARTÍN-BARBERO, J. Dos meios às mediações. Rio de Janeiro: UFRJ, 1997.

MARX, K. O Capital: crítica da economia política. São Paulo: Nova Cultural, 1988.

MATZA, D. As tradições ocultas da juventude. In: BRITTO, S. Sociologia da juventude, III. Rio de Janeiro: Zahar, 1968.

MELO, P. B. A epidemia do consumo, o hedonismo e o dinheiro como distinção: o que a mídia tem a ver com isso? Recife: Terça Psi, Conselho Regional de Psicologia, 2009

Histórias que a mídia conta: o discurso sobre o crime violento e o trauma cultural do medo. Recife: EDUFPE, 2010

MERTON, R. Sociologia: teoria e estrutura. São Paulo: Mestre Jou, 1970

. As consequências não-antecipadas da ação sociIn: A ambivalência sociológica. Rio de Janeiro: Zahar, 1979. p.194-208.

PAIXÃO, A. L. Crime, controle social e consolidação da democracia: as metáforas da cidadania. In: REIS, F. W. O’DONNELL, G. (Org.) A democracia no Brasil: dilemas e perspectivas. São Paulo: Vértice, Revista dos Tribunais, 1988. p. 168-199.

ROCHA, M. E. M. Pobreza e cultura de consumo em São Miguel dos Milagres. Maceió: EDUFAL, 2002.

Consumo traz felicidade? A publicidade no centro da cultura. Revista Comunicação, Mídia e Consumo. São Paulo, v.8, n.23, p.161-179, nov. 2011.

SAUSSURE, F. Curso de linguística geral. São Paulo: Cultrix, 2006.

TASCHNER, G. Cultura, consumo e cidadania. Bauru EDUSC, 2009

Paradoxos da cultura e da comunicação no Brasil do século XXI. In: CONGRESSO INTERNACIONAL DA ASSOCIACÃO LATINO-AMERICANA DE SOCIOLOGIA, 27., 2011, Recife, Anais... Recife: UFPE, 2011.

TONRY, M. Thinking about crime: sense and sensibility in American penal culture. New York: Oxford University Press, 2004.

ZALUAR, Alba. Integração perversa: pobreza e tráfico de drogas. Rio de Janeiro: Ed. FGV, 2004. 


\section{MEDIA, CONSUMPTION AND CRIME IN YOUTH: the construction of a new theoretical tracing}

\author{
Patricia Bandeira de Melo \\ Rodrigo Vieira de Assis
}

Considerations on consumption in modernity open up ways to think about the possibility of the emergence of criminal actions as a means of access to goods, giving to some people the key to belong to social groups, in which one can only take part with the possession of distinctive elements. This paper aims at discussing concepts that can relate to communication, consumption and crime in youth, based on the question: is it possible to establish a connection between the media discourse (direct or subliminal) - a set of journalistic advertising and entertainment narratives on the consumption and use of goods and the construction of youth identity, leading some of them to criminal actions as a way to possess these objects? The understanding of the cultural dimension of the criminal act as a means of access to goods emerges through the interface of studies about consumption, youth and crime.

KEY WORDS: consumption culture, media, significant and meaning, youth, crime.

\section{MÉDIAS, CONSOMMATION ET CRIME DE JEUNESSE: la construction d'un parcours théorique}

\author{
Patricia Bandeira de Melo \\ Rodrigo Vieira de Assis
}

Faire une réflexion sur la consommation dans la modernité conduit à penser qu'il est possible que des actions criminelles surgissent comme moyen d'accès aux biens qui, pour certains individus, ouvrent les portes de groupes sociaux dans lesquels il n'est possible d'entrer que lorsqu'on possède des éléments distinctifs. L'objectif visé dans cet article est de discuter des concepts qui sont en mesure de faire le lien entre la communication, la consommation et la criminalité chez les jeunes en se posant la question suivante: est-il possible qu'il y ait un lien entre le discours des médias (direct ou sous-entendu) - l'ensemble des récits journalistiques, publicitaires et des divertissements sur la consommation et l'usage de biens - et la construction de l'identité des jeunes, les conduisant, pour certains d'entre eux, à commettre des actions criminelles pour accéder à la propriété de ces objets? La compréhension de la dimension culturelle d'un acte criminel en tant que moyen d'accéder aux biens surgit de l'interface d'études réalisées sur la consommation, les jeunes et la criminalité.

Mots-CLÉs: Culture de la consommation. Médias. Signifiant e signifié. Jeunesse. Crime. lhos recentes: Capítulo de livro Criminologia e Teorias da Comunicação. In: Renato Sérgio de Lima; José Luiz Ratton; Rodrigo Azevedo. (Org.). Crime, Polícia e Justiça no Brasil. São Paulo: Contexto, 2014, v.1, p.19; Livro Economia Política da Comunicação: Vanguardismo Nordestino, em co-organização com o professor José Marques de Melo. Recife: Massangana, 2013; Artigo Pânico e controvérsias: história, consumo controlado e tratamento do crack. In: XV Congresso Brasileiro de Sociologia - mudanças, permanências e desafios sociológicos. Curitiba: UFPR, 2011; Artigo Polêmicas no jornalismo do século XXI: discussões a partir da Revista Carta Capital. Contemporânea (UFBA. Online), v. 9, p.115-135, 2011.

Rodrigo Vieira de Assis - Mestrando em sociologia. Membro e assistente de pesquisa do Núcleo de Pesquisas Sociofilo. Trabalhos recentes: Artigo A reconstrução sociológica do conceito de "cultura de consumo". In: XVI Congresso Brasileiro de Sociologia, Salvador, 2013, em coautoria com a professora Maria Eduarda da Mota Rocha (PPGS/UFPE); Capítulo de livro Práticas documentárias e práticas curriculares: anotações sobre a possibilidade de uma educação popular emancipadora em escolas públicas a partir do direito ao narrar. In: MESQUITA, R. G. M. (Org.) Projeto didático para construção de documentários: uma possibilidade de experiência popular em escolas públicas. Recife: EDUFPE, 2013. p. 80-118; Artigo Jovens, consumo cultural e políticas públicas. Revista Habitus, v.10, p.126-142, 2012. 